\title{
Design Analysis of Reciprocating Piston for Single Cylinder Internal Combustion Engine
}

\author{
Ikpe Aniekan Essienubong ${ }^{1 *}$, Owunna Ikechukwu Bismarck ${ }^{1}$ \\ 0000-0001-9069-9676, 0000-0002-6641-0446 \\ ${ }^{1}$ Department of Mechanical Engineering, Faculty of Engineering, University of Benin, Benin City, PMB 1154, Nigeria
}

\begin{abstract}
In this study, CAD model was developed for reciprocating piston of an IC engine using SOLIDWORKS (2017 version) modelling tool and was simulated at a speed of 600-3000 rpm. Reaction forces and linear velocity at different combustion time, thermal stresses, equivalent strains, resultant and displacement on the piston were determined. At an engine speed of $3000 \mathrm{RPM}$ and $224 \mathrm{Nm}$ torque, maximum displacement of $8.03 \times 10-1 \mathrm{~mm}$, maximum equivalent strain of 2.152x10-2 and maximum thermal stress of $24.465 \mathrm{~N} / \mathrm{mm} 2$. The maximum thermally induced stress value fell below the yield strength $(460 \mathrm{~N} / \mathrm{mm} 2)$ of the low alloy steel piston material, indicating that the material still has the capacity to accommodate stresses and deformations before its yield strength is exceeded. It was observed that the higher the engine speed, the higher the reaction forces and resultant displacements on the piston. The highest deformation value was recorded as $13,004.927 \mathrm{~N} / \mathrm{mm} 2$ which occurred at the point where the piston pin and one end of the connecting rod interlocks. Specific attention should be given to the selection of piston material and the intricate environment it operates, as it serves as the heart of a given IC engine.
\end{abstract}

Keywords: Deformation; Displacement; Failure; IC engine; Modelling; Piston, Stress

\author{
* Corresponding author \\ Ikpe Aniekan Essienubong \\ aniekan.ikpe@eng.uniben.edu \\ Address: Department of Mechanical \\ Engineering, Faculty of Engineering, \\ University of Benin, Benin City, \\ Nigeria
}

Tel: +2349024773812

Research Article

$\begin{array}{lr}\text { Manuscript } & \\ \text { Received } & 11.03 .2020 \\ \text { Revised } & 27.03 .2020 \\ \text { Accepted } & 28.03 .2020\end{array}$

Doi: 10.30939/ijastech..702219

\section{Introduction}

A piston is a component of reciprocating internal combustion (IC) engines. It is the moving component that is contained by a cylinder which through the help of the piston rings achieve an air-tight condition for effective combustion process [1]. A typical IC engine piston consists of the piston crown which carries the gas pressure, skirt which serves as a bearing against the side thrust of the connecting rod, piston pin which connects the piston to the connecting rod and the piston ring which seals the annular space between the cylinder wall and the piston $[2,3]$. The primary function of a reciprocating piston is to transfer force from expanding gas in the cylinder to the crankshaft through a piston rod and/or connecting rod $[4,5]$. In other words, the fuel upon burning changes into hot gases which impacts on the piston and causing reciprocating motion which in the process is converted into rotary motion of the crank shaft [6]. The major forces acting on the piston as it reciprocates within the cylinder is the force of inertia resulting from the high frequency of reciprocating motion of the piston, friction between the cylinder walls as well as the forces from the hot expanding gases [7]. Due to the high temperature (up to $2500 \mathrm{k}$ ) and pressure condition of an engine, the piston undergoes cyclic gas pressure and the inertial forces at work, and this working condition may result in fatigue damage, wear, cracks etc. [8]. The high temperature due to the burning gas results in the expansion of the piston material, thereby, causing thermal stress and deformations which are at the expense of the piston material properties [9]. Nigus [10] investigated the kinematics of an internal combustion engine crank mechanism. The Kinematics formulation of the crank mechanism was done using vector loop method 
and cosine rule with respect to the position of the reciprocating piston. The forces acting on the reciprocating piston and the torque applied were also formulated based on the angles of the crank and connecting rod. Comparative static stress analysis was performed by Vishal et al. [11] at different pressure load condition of reciprocating piston designed with two aluminium alloy materials (A4032 and AL-GHY1250). From the result obtained, AL-GHY-1250 had a lower deformation throughout the pressure loads compared to A4032. The lower deformation observed in AL-GHY-1250 was as a result of its higher yield strength and ultimate tensile strength when compared to those of A4032. Numerical and experimental investigation of the effects of partially thermal barrier coating on piston temperature distribution and cold start $\mathrm{HC}$ emissions of a spark ignition (SI) engine was carried out by Cerit et al. [12]. The result showed an increase up to $100 \mathrm{oC}$ in the surface temperature of the coated piston part, which led to an increase in the air fuel mixture temperature in the crevice and wall quenching region. Thus, cold start HC emissions considerably decrease compared to the standard engine. Manisaikamal [13] carried out structural and thermal analysis of IC engine piston head with concave and convex shapes. The stress distribution and total deformation observed in concave shaped piston head were higher compared to those observed in convex shape piston head. Moreover, heat distribution observed in convex shape piston head was lower than that of concave shape piston head. The low heat distribution will result in increased life of the piston rings and piston pin as well as minimal exposure to thermal fatigue. The internal combustion engine is a system that converts the chemical energy sored in the combusting air-fuel mixture in IC engine cylinder to Kinetic energy in a driveshaft. This heat is then converted to kinetic energy on the piston face and down to the connecting rod which in turn rotates the crankshaft. During the process, stresses and deformations are induced in the materials that transmit these forces as they are subjected to great heat and force. In this study, the engine casing as well as the piston assembly was modelled and the thermodynamic condition that occurs in a typical IC engine cylinder was simulated to determine the effects of the resulting heat and forces on the piston component.

\section{Materials and Methods}

As shown in Fig. 1, the Computer Aided Design (CAD) drawings were modelled using SOLIDWORKS 2017 version. A 2D schematic diagram developed for the piston assembly is presented in Fig. 2 and Fig. 3. Finite Element Method (FEM) was employed for static nodal simulation of the piston and connecting rod to check the level of deformation in terms of the displacement and stress induced on the piston assembly. The same analysis was also repeated, but to determine the stress and strain along the piston within an enclosed IC engine cylinder. From the simulated models, the reaction forces as well as linear velocity of the hot gas was determined. The mesh information applied in the modelling is presented in Table 1 while the materials and justification selected for the reciprocating piston assembly are shown in Table 2.

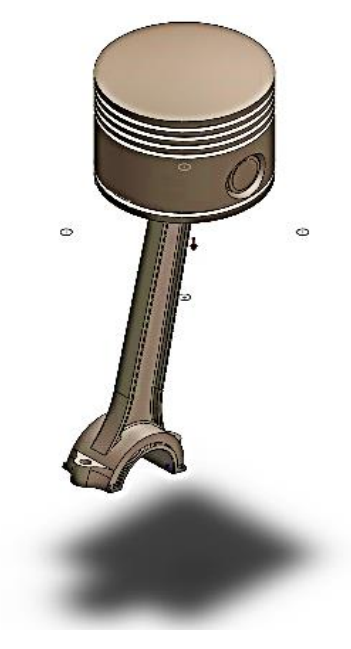

b.

b. CAD model of the reciprocating piston

Fig. 1. a. CAD model of the engine casing 


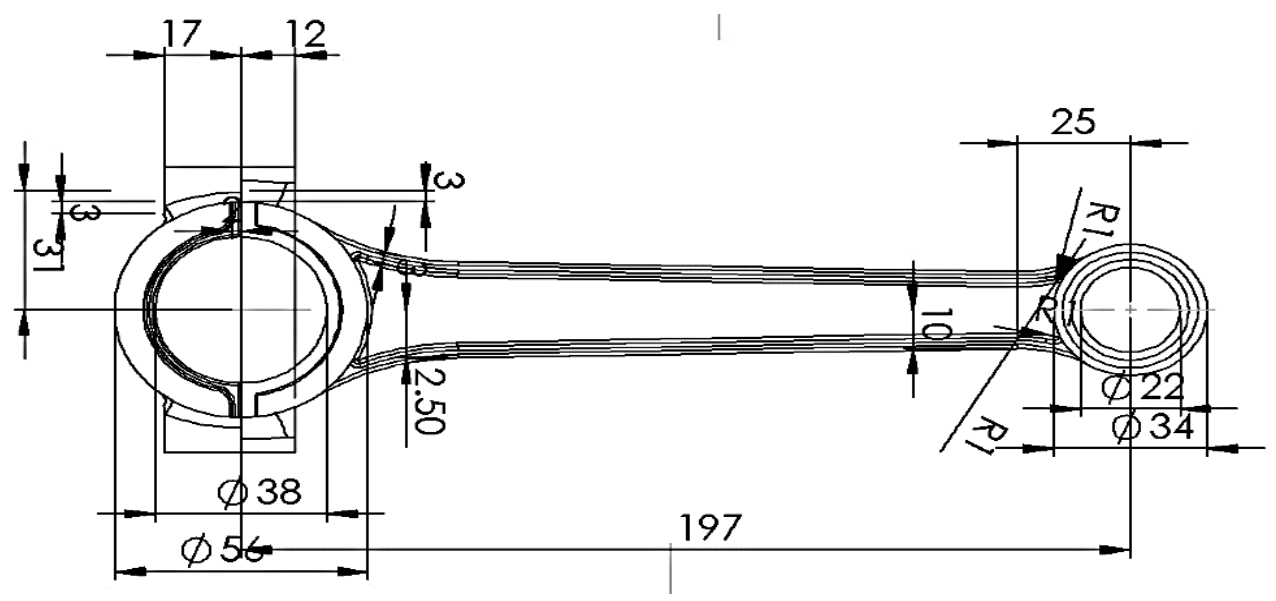

Fig. 2. Schematic diagram of the fully dimensioned connecting rod
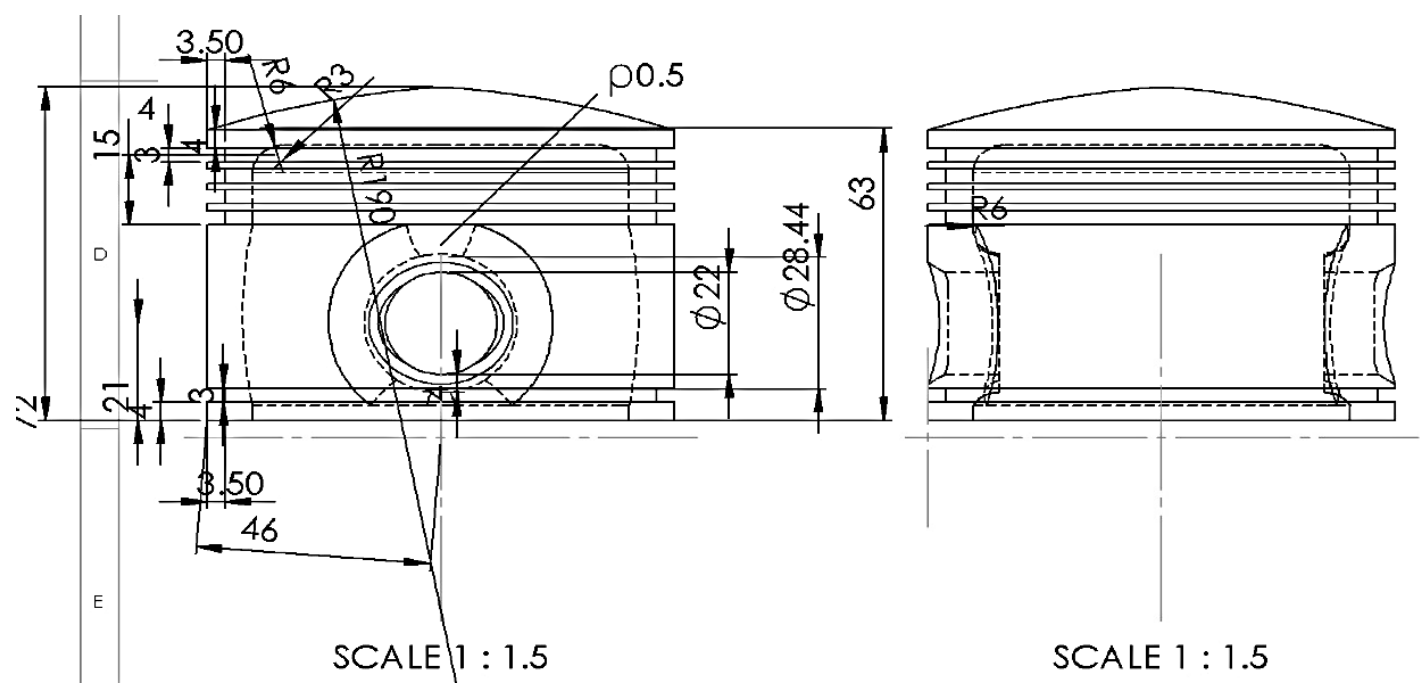

SCALE $1: 1.5$

Fig. 3. Schematic diagram of the fully dimensioned piston crown

Table 1: Mesh information for the reciprocating piston

\begin{tabular}{c|c|c|c}
\hline \multicolumn{2}{c|}{ Mesh Information for Piston } & \multicolumn{2}{c}{ Engine Model specification } \\
\hline Mesh type & Solid Mesh & Compression ratio (r) & 10.3 \\
\hline Mesher Used & Curvature based mesh & Expansion coefficient (k) & 1.4 \\
\hline Jacobian points & 4 Points & Engine speed (RPM) & 3000 \\
\hline Max element size & $7.57717 \mathrm{~mm}$ & Bore (mm) & 81 \\
\hline Min element size & $1.51543 \mathrm{~mm}$ & Mass of piston (Ibs) & 1 \\
\hline Mesh Quality & High & Ratio of crank to connecting rod length & 0.35 \\
\hline Analysis type & Static nodal & Clearance volume (litres) & 0.05 \\
\hline Solver type & FFEPlus & Mass of connecting rod (Ibs) & 1.75 \\
\hline
\end{tabular}


Table 2. Material selection for various parts of the piston assembly

\begin{tabular}{|c|c|c|}
\hline Component & Material & Justification \\
\hline Piston & Low Alloy Steel & $\begin{array}{l}\text { Designed for strength, cheaper, toughness at low temperature, ade- } \\
\text { quately ductile and weldable. }\end{array}$ \\
\hline Piston pin & High carbon steel & Increased strength and hardness, poor weldability. \\
\hline Piston Pin Plug & Low Carbon Steel & Excellent weldability, good balance of toughness. \\
\hline Connecting Rod & High Carbon Steel & $\begin{array}{l}\text { Designed for strength, cheaper, toughness at low temperature, ade- } \\
\text { quately ductile and wieldable. }\end{array}$ \\
\hline Crankcase Top & $\begin{array}{l}\text { Aluminium alloy (2014- } \\
\text { T6) }\end{array}$ & $\begin{array}{l}\text { High strength to weight ratio, excellent corrosion resistance, good } \\
\text { conductor of heat and electricity. }\end{array}$ \\
\hline Engine Body & $\begin{array}{l}\text { Aluminium alloy (2014- } \\
\text { T6) }\end{array}$ & $\begin{array}{l}\text { High strength to weight ratio, excellent corrosion resistance, good } \\
\text { conductor of heat and electricity. }\end{array}$ \\
\hline
\end{tabular}

The mean piston velocity of the two stroke engine is given by Equation 1.

$v_{p}=\frac{2 L N}{60}$

Where $v p$ is the mean piston velocity, $L$ is the piston stroke from Top Dead Centre (TDC) to Bottom Dead Centre (BDC), $\mathrm{N}$ is the engine speed. The instantaneous position of the piston from piston pin center to TDC is given by Equation 2.

$x=l\left(\lambda^{2} \sin ^{2} \theta / 2\right)+r(1-\cos \theta)$

Where, $\lambda$ is the ratio of crank radius to connecting rod length, $l$ is the length of connecting rod. The instantaneous piston velocity of the piston on the crank mechanism is expressed in Equation 3.

$v_{\text {ins }}=\frac{d x}{d \theta} \frac{d \theta}{d t}=\frac{d x}{d \theta} \frac{2 \pi N}{60}$

From Equation 3, the angular piston velocity is derived as shown in Equation 4.

$$
\omega=\frac{d \theta}{d t}=\frac{2 \pi N}{60}
$$

Where, $d x$ is derivative of piston instantaneous position, $d \theta$ is derivative of crank angle, $d t$ is the time derivative, $\omega$ is the angular piston velocity. Substituting the first derivative in Equation 2, with respect to crank angle is given by Equation 5;

$$
v_{i n s}=r \omega\left\{\sin \theta+\frac{\lambda \sin 2 \theta}{2}\right\}
$$

The piston instantaneous acceleration $\left(a_{i n s}\right)$ is given as by Equation 6. This is express in the same format as the instantaneous velocity,

$$
\begin{aligned}
& a_{i n s}=\frac{d v_{i n s}}{d t}=\frac{d v_{i n s}}{d \theta} \frac{d \theta}{d t} \\
& a_{i n s}=r \omega^{2}\{\cos \theta+\lambda \cos 2 \theta\}
\end{aligned}
$$

The relationship between the crank radius and connecting rod length and distance from piston pin axis to crank axis is illustrated

in Fig. 4.

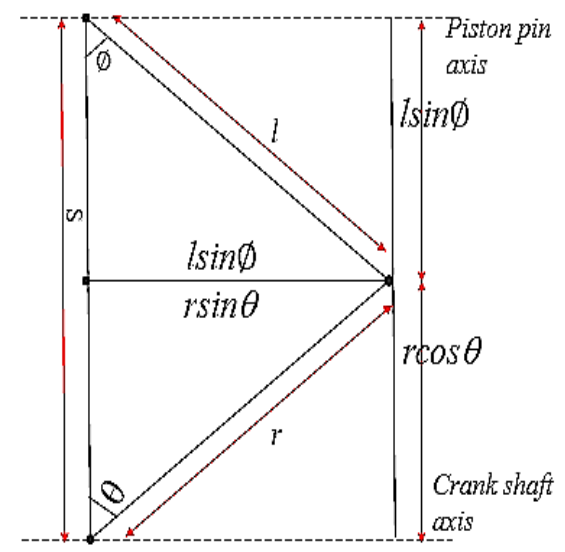

Fig. 4. Schematic diagram of the reciprocating piston angles

As shown in Equation 7, piston pin position is the position from the crank centre to the piston pin centre and is formulated from cosine rule of the trigonometry in Fig. 4,

$l^{2}=r^{2}+S^{2}-2 r s \cos \theta$

From the above polynomial equation (see Equation 7) the piston position can be derived as expressed in Equation 8,

$S=r \cos \theta \pm \sqrt{l^{2}+r^{2} \sin ^{2} \theta}$

With respect to angle $\theta$ in Fig. 4, piston pin velocity is the upward velocity from crank centre along cylinder bore centre and can be calculated as the first derivative of Equation 7. Therefore,

$v=-r \sin \theta-\frac{r^{2} \sin \theta \cos \theta}{\sqrt{l^{2}+r^{2} \sin ^{2} \theta}}$ 
Also with respect to angle $\theta$ in Fig. 4, piston pin acceleration is the upward acceleration from crank centre along cylinder bore centre and can be expressed as the second derivative of Equation 7,

$a=-r \cos \theta-\frac{r^{2}\left(\cos ^{2} \theta-\sin ^{2} \theta\right)}{\sqrt{l^{2}+r^{2} \sin ^{2} \theta}}-\frac{\left(r^{2}\right)^{2} \sin ^{2} \theta \cos ^{2} \theta}{\sqrt{l^{2}+r^{2} \sin ^{2} \theta}}$

The connecting rod is a major link inside of a combustion engine. It connects the piston to the crankshaft and is responsible for transferring power from the piston to the crankshaft and sending it to the transmission. Instantaneous velocity of the connecting rod is given by Equation 11, while the instantaneous acceleration of the connecting rod is given by Equation 12,

$v_{\text {con }}=\frac{d \emptyset}{d t}=\frac{d \emptyset}{d \theta} \frac{d \theta}{d t}$

$a_{\text {con }}=\frac{d v_{c o n}}{d t}=\frac{d v_{c o n}}{d \theta} \frac{d \theta}{d t}$

According to Nigus [10], the forces acting on the crank reciprocating piston includes; the gas force $\left(F_{g}\right)$ acting on the piston, side thrust or normal force $\left(F_{N}\right)$ acting on the direction of the piston pin, vertical reaction force $\left(F_{R}\right)$, tangential forces $\left(F_{T}\right)$, connecting rod forces $\left(F_{c r}\right)$, Force of inertia $\left(F_{I}\right)$, reacting force by cylinder inner wall. Represented by Equation 13, the gas force is the product of maximum pressure and area of the cylinder, while the torque resulting only from the gas pressure is given by Equation 14:

$F_{g}=P_{\max } \frac{\pi B^{2}}{4}$

$T_{g}=P_{g} \operatorname{Ar} \sin \theta\left[1+\frac{r}{l} \cos \theta\right]$

Where $T_{g}$ is the gas torque, $P_{g}$ is the gas pressure, $A$ is the area of the piston top. Represented by Equation 15, inertia force is can be obtained by multiplying the piston acceleration by the reciprocating mass and acts only in the line of the cylinders.

$F_{i}=M_{R E C} r \omega^{2}\left[\begin{array}{cc}\cos \theta+\frac{r}{l} & \cos 2 \theta \\ -\frac{1}{4} \frac{r^{3}}{l^{3}} & \cos 4 \theta\end{array}\right]$

Where, MREC is the reciprocating mass (piston mass plus approximately $2 / 3$ conrod mass). Given by Equation 16 , the torque resulting from piston motion is referred to as the "inertia torque",

$\mathrm{T}_{\mathrm{I}}=\mathrm{M}_{\mathrm{REC}} \mathrm{r}^{2} \omega^{2}\left[\begin{array}{c}\frac{\mathrm{r}}{4 \mathrm{l}} \sin \theta- \\ \frac{1}{2} \sin 2 \theta \frac{3 \mathrm{r}}{4 \mathrm{l}} \sin 3 \theta\end{array}\right]$
Considering the piston pin at a fixed position, the forces acting on the piston at different co-ordinates can be expressed (see Equations 17-19) as the inertia force $\left(F_{i x}\right)$ in the horizontal, the inertia force $\left(F_{i y}\right)$ in the vertical direction and the inertia force $\left(M_{i \theta}\right)$ in the rotational direction.

$F_{i x}=m_{p} \ddot{x}_{C O G}=m_{p}\left\{\ddot{x}_{p}+s\left(\ddot{\theta}_{p} \cos \left(\gamma+\theta_{p}\right)-\right.\right.$ $\left.\left.\dot{\theta}_{p}^{2} \sin \left(\gamma+\theta_{p}\right)\right)\right\}$

$F_{i y}=m_{p} \ddot{y}_{C O G}=m_{p}\left\{\ddot{y}_{p}-s\left(\ddot{\theta}_{p} \sin \left(\gamma+\theta_{p}\right)+\right.\right.$

$\left.\left.\dot{\theta}_{p}^{2} \cos \left(\gamma+\theta_{p}\right)\right)\right\}$

$M_{i \theta}=I_{p} \ddot{\theta}_{C O G}=I_{p} \ddot{\theta}_{P}$

Where, $m_{p}, I_{p}$ are the mass and mass moment of inertia of piston, $s$ is the piston pin offset distance, $\gamma$ is the piston pin offset angle. Considering the above forces in Equations 1719 , equations of motion describing the piston response under these forces are given in the following relationships ( see Equations 20-22).

$m_{p}\left\{\ddot{x}_{p}+s\left(\ddot{\theta}_{p} \cos \left(\gamma+\theta_{p}\right)-\dot{\theta}_{p}{ }^{2} \sin \left(\gamma+\theta_{p}\right)\right)\right\}=$

$A_{x}+F_{A}+F_{B}-F_{C}-F_{D}$

$m_{p}\left\{\ddot{y}_{p}-s\left(\ddot{\theta}_{p} \sin \left(\gamma+\theta_{p}\right)+\dot{\theta}_{p}{ }^{2} \cos \left(\gamma+\theta_{p}\right)\right)\right\}=$

$-A_{y}-F_{\text {gas }}-F_{\text {fric }}-m_{p} g$

$I_{p} \ddot{\theta}_{p}=F_{g a s}\left(x_{B O}-x_{p}\right)+F_{A} l_{y A}-F_{B} l_{y B}-F_{C} l_{y C}+$

$F_{D} l_{y D}+m_{p} g \cdot s \sin \left(\gamma+\theta_{p}\right)-T_{\text {fric }}+m_{p} \ddot{x}_{p} l_{y}-$

$m_{p} \ddot{y}_{p} l_{x}$

\section{Results and Discussion}

The finite element method employed in this study for the analysis of an IC engine reciprocating pistion in this study is a computer simulation approach that replicates the working condition of the piston in a typical IC engine cyliner. The working condion of a two stroke piston engine is known to occur in downstroke and upstroke namely;

i. Down stroke: The piston moves downward from top dead center, TDC to the bottom dead center, BDC. As the piston moves, low pressure forms in the cylinder, and an air-fuel mixture at the ambient temperature and pressure (a little less than the ambient pressure) enters into the combustion chamber through the crankcase. At this point, the crankshaft rotation is at an angle of $180 \mathrm{o}$.

ii. Up stroke: The inlet valve closes, and the piston moves from the BDC to the TDC. In this process, both the air-fuel mixture's, pressure as well as the temperature increases and are compressed. During this process, the piston does work on the gas in the combustion chamber. At 
some point during the process, the spark plug fires, ignites the mixture and combusts the fuel, raising both the temperature and the pressure of the gas. As the air-fuel mixture gets expanded in th combustion chamber, the piston moves downwards the cylinder. During the upward stroke, the inlet port opens and the mixture is sucked into the crankcase. As the air-fuel mixture is pushed upwards into the combustion chamber, a vacume is partially created as no mixture is left in the crankcase. In the second downword stroke onwards, the combusted gas is expelled out from one while while a fresh mixture enter the combustion chamber. From the aforementioned process,

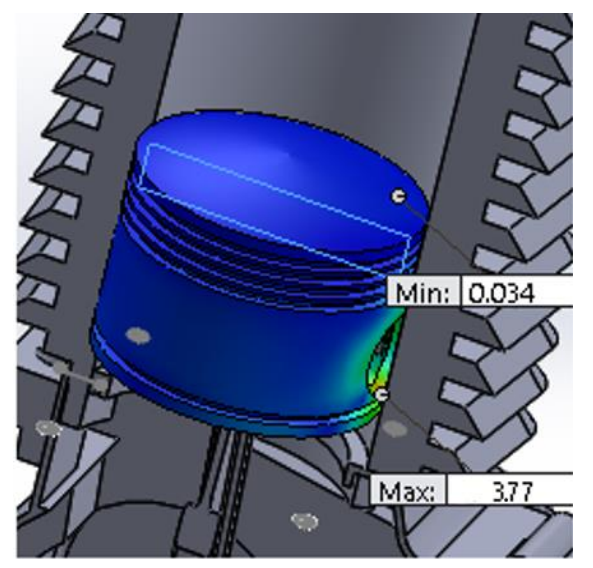

a two strokes get completed in only one power cycle. It can be observed in Fig. 5a that the maximum molar heat capacity $(3.77 \mathrm{~J} / \mathrm{mol} . \mathrm{k})$ is lower when the piston crown is at the mid-section of the IC engine cylinder but increased (7.072 J/mol.k) when the piston crown approached the TDC as shown in Fig. 5b. This implies that it takes $3.77 \mathrm{~J}$ of heat to raise $1 \mathrm{~mol}$ of hot gas by 1 degree kelvin to the midsection of the IC engine cylinder. Increase in the molar heat capacity as the piston crown aproaches the TDC is due to the hot compressed air-fuel mixture traped at the TDC of the piston stroke.

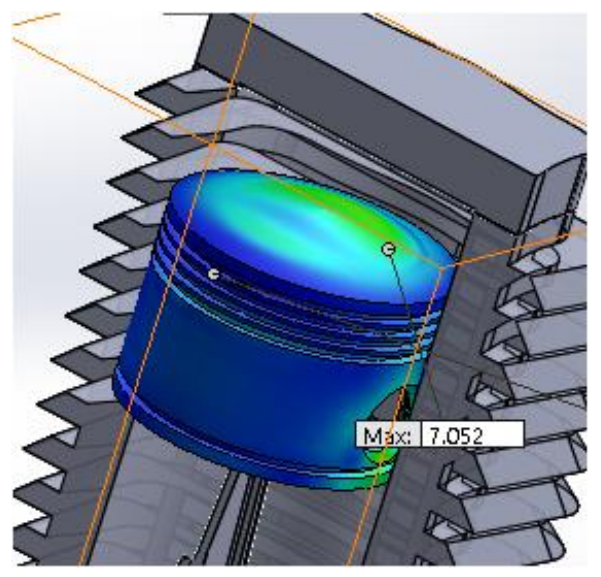

b

Fig. 5. a. Molar heat capacity at mid-section of cylinder b. Molar heat capacity towards TDC

The pressure of the gases (air + fuel, or by products of combustion) exerts a force on the piston. The combustion products also impacts on the reciprocating engine as it move upwards and downwards the IC engine cylinder. The chemical and thermal reaction in the cylinder during combustion interacts with the Brownian motion of the gas pressure inside the cylinder. This in effect exposes the reciprocating piston and its entire assembly to extreme conditions characterized by thermal stresses and strain resulting from thermal expansion of the piston material in the hot combustion environment. The thermal expansion which causes gradual increment in the size and geometry of the piston assembly also known as deformation gives rise to displacement of the piston which occurs mostly in areas with two or more connection, such as the point where the connecting rod interlocks with the piston crown via the piston pin. The aforementioned effects due to the reactions in the IC engine cylinder is presented in Table 3. In this case, it was assumed that the engine is running at constant speed. This is at best an approximation since the engine speed is never constant but instead fluctuates within a narrow band. However, assuming this approximation is valid, the angular acceleration of the piston will be zero.

Table 3. Computation of piston displacement and thermal stresses at different engine speeds

\begin{tabular}{c|c|c|c|c}
\hline S/N & Engine speed $(\mathrm{RPM})$ & Torque $(\mathrm{Nm})$ & Displacement $(\mathrm{mm})$ & Thermal stress $(\mathrm{N} / \mathrm{mm} 2)$ \\
\hline 1 & 600 & 171 & $1 \times 10^{-30}$ & 0.043 \\
\hline 2 & 800 & 176 & $6.692 \times 10^{-2}$ & 2.078 \\
\hline 3 & 1000 & 180 & $1.338 \times 10^{-1}$ & 4.114 \\
\hline 4 & 1200 & 184 & $2.008 \times 10^{-1}$ & 6.149 \\
\hline 5 & 1400 & 187 & $2.677 \times 10^{-1}$ & 8.184 \\
\hline 6 & 1600 & 192 & $3.346 \times 10^{-1}$ & 10.219 \\
\hline 7 & 1800 & 196 & $4.015 \times 10^{-1}$ & 12.254 \\
\hline 8 & 2000 & 199 & $4.684 \times 10^{-1}$ & 14.289 \\
\hline 9 & 2200 & 203 & $5.353 \times 10^{-1}$ & 16.325 \\
\hline 10 & 2400 & 208 & $6.023 \times 10^{-1}$ & 18.360 \\
\hline 11 & 2600 & 211 & $6.692 \times 10^{-1}$ & 20.395 \\
\hline
\end{tabular}




\begin{tabular}{|c|c|c|c|c|}
\hline 12 & 2800 & 218 & $7.361 \times 10^{-1}$ & 22.430 \\
\hline 13 & 3000 & 224 & $8.03 \times 10^{-1}$ & 24.465 \\
\hline
\end{tabular}

According to Ikpe et al. [14], Von-mises stress criterion helps in predicting the yield point of a material when subjected to complex loading conditions. The Von-mises failure theory states that a given material under the influence of forces is prone to failure if the Von mises stress resulting from the reaction forces exceed the material yield strength, but if the Von-mises stress value is less than the material's yield strength, such material still has the capacity to accommodate additional forces [15]. This relates to the theory behind elasticity of materials which states that the material can take additional load provided its elastic limit is not exceeded [16]. Considering the material yield strength of 460 $\mathrm{N} / \mathrm{mm} 2$, maximum Von-mises thermal stress of 24.465 $\mathrm{N} / \mathrm{mm} 2$ and the maximum equivalent strain of 0.02152 obtained for the piston component in the simulated result in Fig. 6, it can be observed that the maximum Von-mises stress obtained is below the yield strength of the materials, which implies that the piston despite the harsh operational condition can still accommodate additional forces until the yield strength of the material is exceeded.

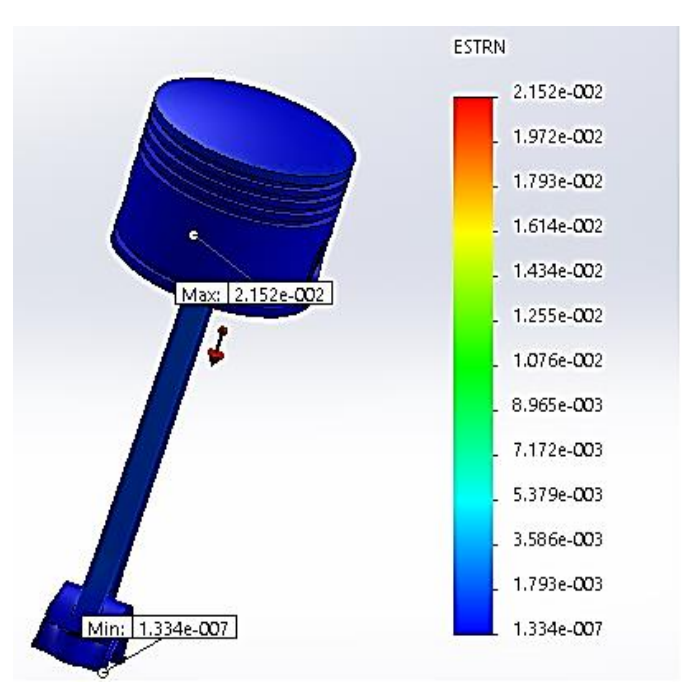

a

Fig. 6. a. Equaivalent strain on the piston

Since the piston pin position differs from the center of gravity of a reciprocating piston within the engine cylinder, moment about the piston pin is developed by the side thrust force, which in principle is the lateral component of the force induced by the connecting rod. Therefore, rotational motion of the piston is inevitable. In cases where the piston collides against the inner wall of the cylinder, piston skirt contacts firstly. While the side thrust force constantly impacts on the piston, the lateral area of the reciprocating piston collides with the inner walls of the IC engine cylinder. This process gives rise to displacement of the reciprocating piston as presented in Fig. 7.

It is important to calculate the piston temperature distribution in order to control the thermal stresses and deformations within acceptable levels. The thermal reaction resulting from linear expansion and phase transformation can

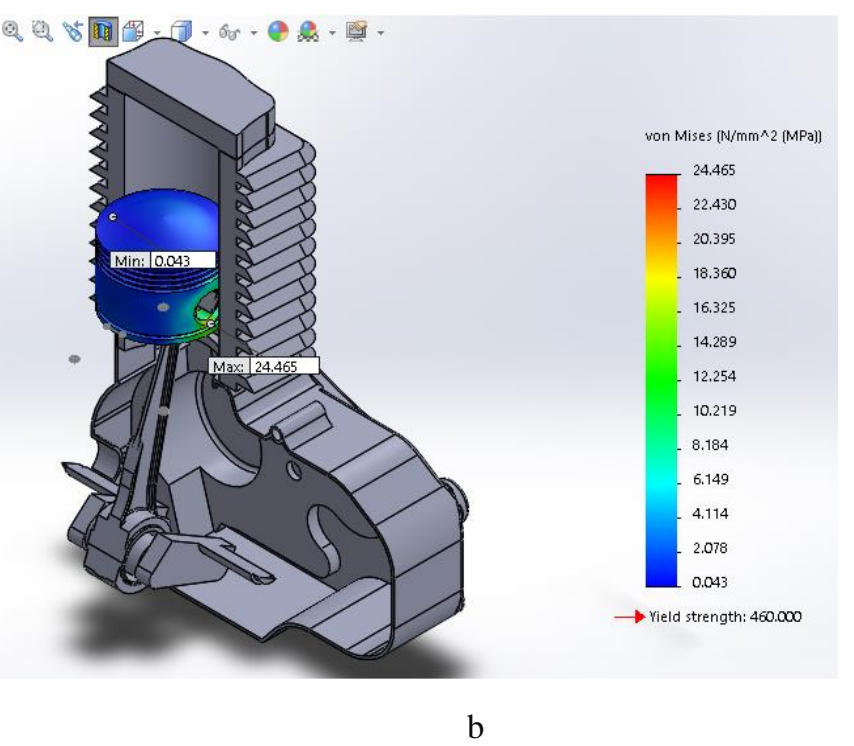

b. Thermal stress distribution on the piston

be due to increase in specific heat $(\mathrm{Cp})$ input in the temperature between solidus and liquidus temperature range. In this case, the atoms and electrons within the microstructure of the piston material continues to absorb heat until a point is reached where thermal equilibrium or saturation is attained and the material begins to fail [17]. According to Owunna and Ikpe [18], the thermal conductivity of a metal is affected by several factors including temperature, atomic structure, phase transformation, grain size, chemical composition etc. and this can subject the piston material to high thermal stresses, causing residual stress build-up. As shown in Fig. 6b, thermal stresses impacting on the piston is as a result of the change in working temperature of the material, specific heat capacity of the hot gases and the rate of internal heat in the cylinder which are all dependent on the temperature in the cylinder during working cycle. 

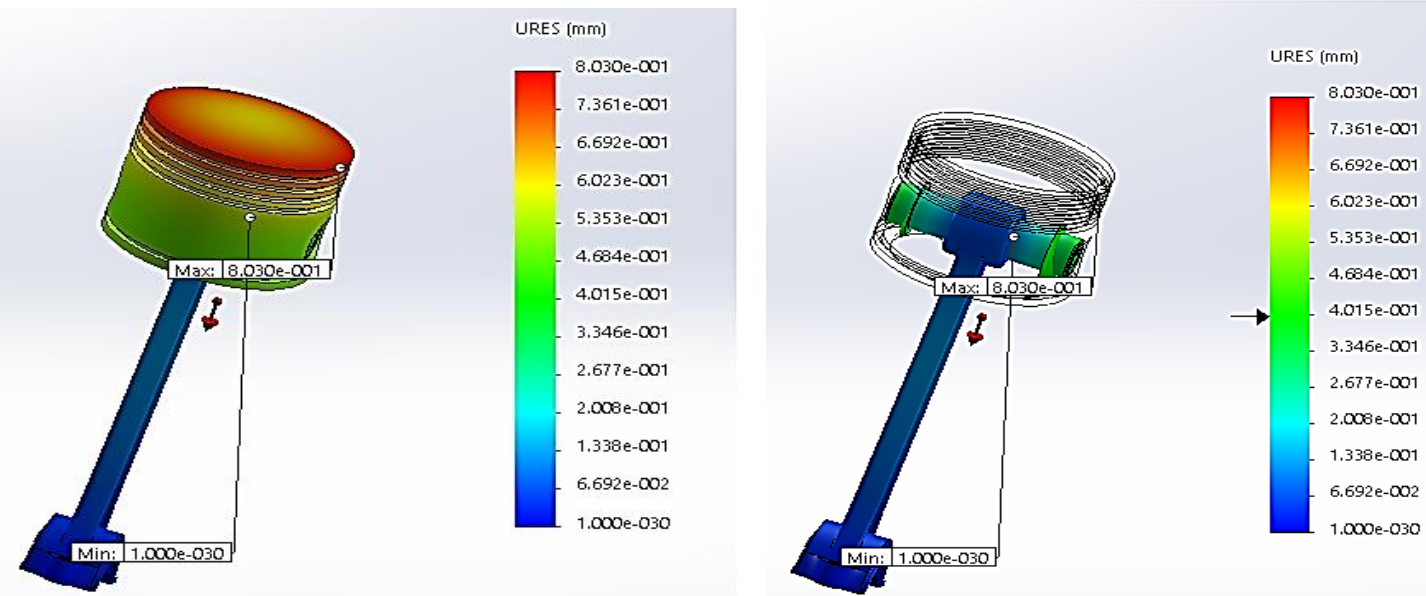

Fig. 7. Displacement level on the reciprocating piston

Most of the Internal Combustion (IC) engine pistons are made of an aluminium alloy which has a thermal expansion coefficient, $80 \%$ higher than the cylinder bore material made of cast iron [8], while coating is sometimes applied on the piston to serve as thermal barrier and to reduce thermal stress on the material while improving the thermal efficiency of the engine [19]. It is important for manufactures to pay attention to the piston-con rod material arrangement, as negligence in such case may result in severe deformation.
This implies that the operation of the piston without coating on the material or the use of materials that are poor heat conductors in the area of such assembly may result in unforeseen failure of the piston. As shown in Fig. 8, the highest deformation $(13,004.927 \mathrm{~N} / \mathrm{mm} 2)$ on the piston assembly occurred on the area where the connecting rod interlocks with the piston pin while the minimum deformation occurred on the connection point between the other end of the connecting rod and the crankshaft.
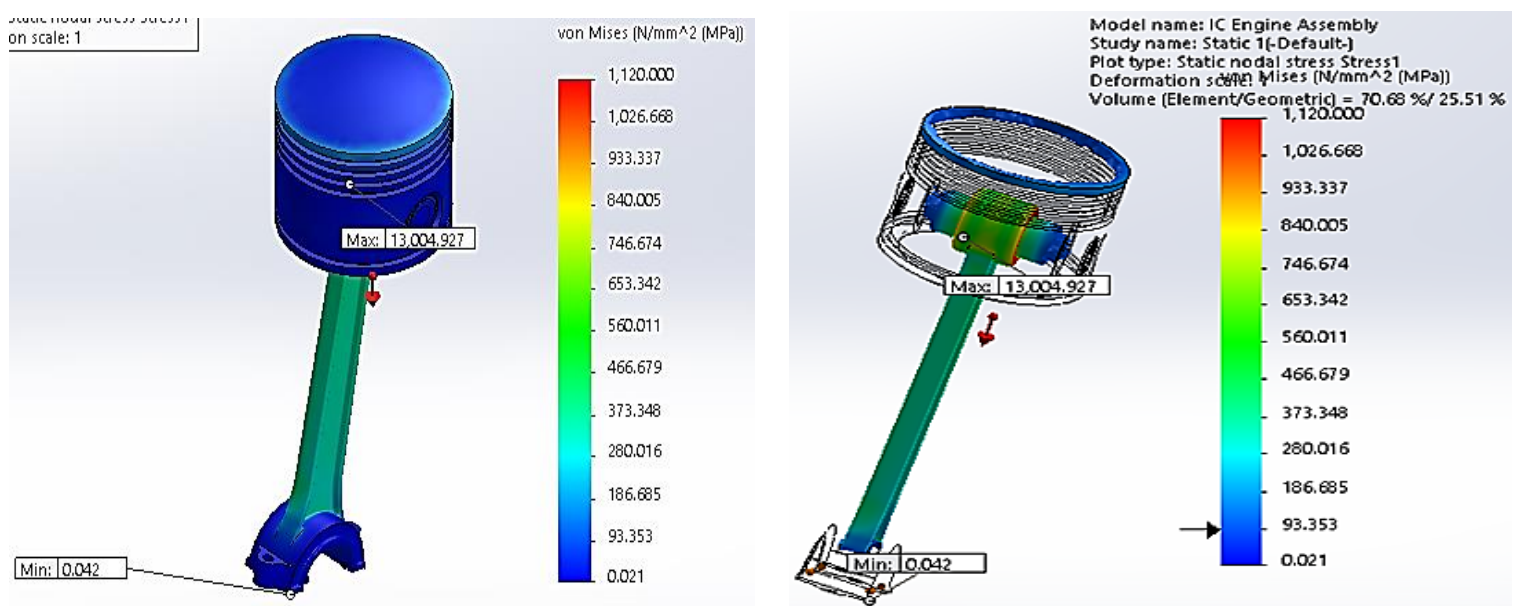

Fig. 8. Resultant deformation on the Piston assembly

Fig. 9 represents a plot of reaction forces on piston against time while Fig. 10 represents a plot of linear velocity of combusted gases against time. It can be observed that the trend of the graph is sinusoidal in nature. The plots in Fig. 9 and Fig. 10 indicates that both reaction forces on the piston and linear velocity of the combusted gases increases and decreases simultaneously as the reciprocating cycle of the piston progresses with time. The sinusoidal trend of the graph in Fig. 9 represents the upward and downward movement of the piston which clearly shows the different points in terms of time intervals when the piston is exposed to reaction forces before completing one reciprocating cycle. The graph in Fig. 10 which also have the same sinusoidal pattern with Fig. 9 indicates the rate of change of displacement of the combusted gases with respect to the time intervals when the piston moves upward or downward along a 
straight path within the cylinder. Similar to Fig. 9, the different points in terms of the time interval when the incylinder combusted gases expands and is displaced linearly along the cylinder before completing one reciprocating cycle are also depicted graphically in Fig. 10. The expanded gases impacts on the piston as it moves along the cylinder, thereby, causing vibration and other unwanted effects that can disrupt the performance of a vehicle. All these conditions and many other conditions that have not been considered in this study forms part of the loading factors that eventually causes failure of the piston in its duty cycle. The reciprocating piston during operation, is subjected to variable or alternating loads/forces also referred to as fluctuating or fatigue loads which are attributed to the vibratory effect when the engine undergoes variation in speed, expansion of the in-cylinder air-fuel mixture and the reciprocating movement of the piston in the cylinder with time. As the forces continue to act on the piston throughout its upward and downward motion over time, a point is reach where the material begins to deform. The effect of such action begins to expose the piston material to fluctuating stress which sometimes trigger failure at stress level much lower than the ultimate strength of the material and in some cases lower than the yielding point of the material. The aforementioned failure events may occur as a result of extremely large cycles of stress, and are referred to as fatigue failure. Also, the piston studied in this paper was designed from ductile material as shown in Table 2 . From the principles of plasticity theory, when load is applied on a ductile material, plastic deformation occurs evenly across the material, and continues as the load increases. The tensile deformation is followed by necking which indicate the parts where relatively large amount of strain localize disproportionately in a small region of the piston material prior to the occurrence of failure [20].

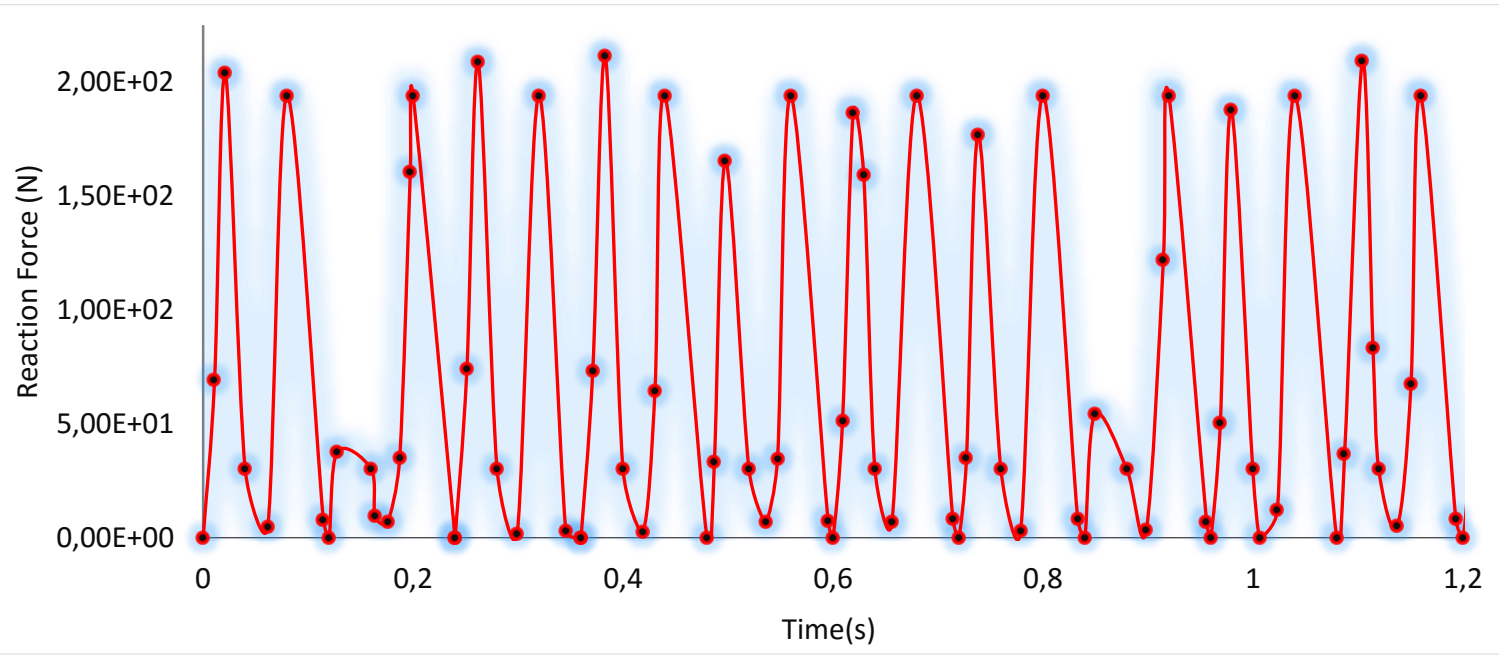

Fig. 9. Plot of reaction forces on piston against time

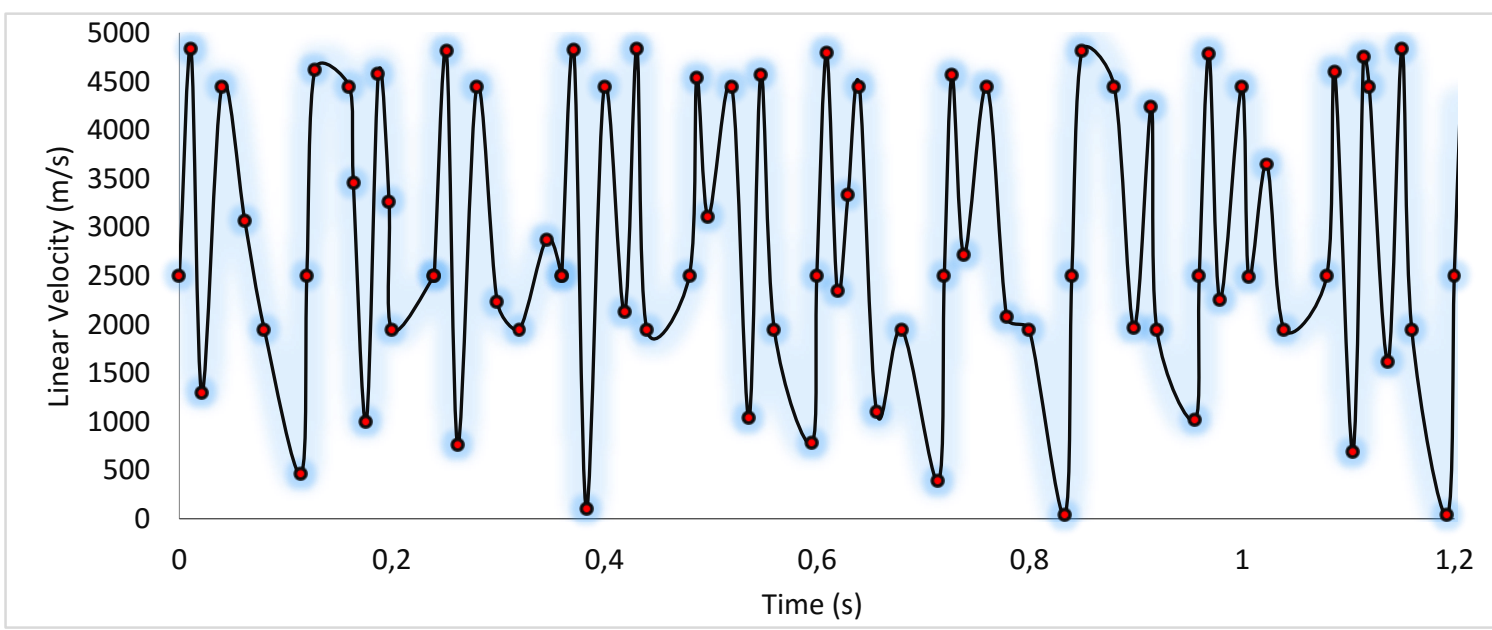

Fig. 10. Plot of linear velocity of combusted gases against time 


\section{Conclusion}

Using FEM, reciprocating piston of an IC engine was successfully modelled and simulated, and response of the piston material to the reaction forces and hot got gases during the upward and downward stroke of the piston was analysed. The result of the analysis indicated that the higher the reciprocating speed of the piston (engine speed), the higher the torque transmitted to the crankshaft for rotation. The higher engine speed and torque gives rise to the temperature of the hot gases while the velocity of the hot gasses accelerates rapidly within the confined space of the engine cylinder bore. This in turn induces thermal stress and strain on the piston material as well as displacement and deformation which can limit the longevity and performance of the piston in service condition. With the advancement in material science, materials with good thermal conductivity, light weight to strength ratio and good mechanical properties must be considered for IC engine pistons in order to function optimally.

\section{References}

[1] Sathish, K. K. (2016). Design and analysis of IC engine piston and piston ring on composite material Using Creo and Ansys software, Journal of Engineering and Science, 1(1), 39-51.

[2] Balahari, K. S., Aezhisai, V. M., Arunkumar, M. and Haripraveen, A. (2017). Design and analysis of an IC engine piston using composite material, European Journal of Advances in Engineering and Technology, 4(3), 209-215.

[3] Ikpe, A. E. and Owunna, I. B. (2020). A 3d modelling of the in-cylinder combustion dynamics of two stroke internal combustion engine in its service condition, Nigerian Journal of Technology, 39(1), 161-172.

[4] Sonar, D. K. and Chattopadhyay, M. (2015). Theoretical analysis of stress and design of piston head using Catia and Ansys, International Journal of Engineering Science Invention, 4(6), 52-61.

[5] Prasas, G. S., Achari, K. D., Goud, E. K., Nagaraju, M. and Srikanth, K. (2016). Design and analysis of internal combustion engine on different materials using CAE tool Ansys, International Journal of Engineering and Techniques, 2(3), 1-7.

[6] Kumar, M. P. and Adinarayana, S. (2017). Design optimization of piston of an IC engine and investigation on its influence on overall assembly, International Journal of Engineering Science and Computing, 7(6), 13542-13551.

[7] Gadde, A. K. and Raj, C. N. (2017). Design and analysis of an IC piston and piston rings by using three different materials, International Journal of Advances in Mechanical and Civil Engineering, 4(2), 20-25.

[8] Reddy, S. S. and Kumar, B. S. (2013). Thermal analysis and optimization of IC engine piston using finite element method, International Journal of Innovative Research in Science, En- gineering and Technology, 2(12), 7834- 7843.

[9] Gupta, A. K. and Tripathi, V. K. (2014). Design analysis and optimization of internal combustion engine piston using CEA Tool ANSYS, International Journal of Engineering Research and Applications, 4(11), 4-10.

[10] Nigus, H. (2015). Kinematics and load formulation of engine crank mechanism, Mechanics, Materials Science and Engineering, ISSN: 2412-5954.

[11] Vishal, J., Jain, R. K., Chauhan, Y. S. (2016). Stress analysis of IC engine piston for different materials and pressure load using FEA, International Journal of Engineering Sciences and Research Technology, 5(7), 340-350.

[12] Cerit, M., Ayhan, V., Parlak, A., Yasar, H. (2011). Thermal analysis of a partially ceramic coated piston: Effect on cold start $\mathrm{HC}$ emission in a spark ignition engine, Thermal Engineering, 31,336-341

[13] Manisaikamal, D. (2017). Structural and thermal analysis of IC engine piston head with concave and convex shapes, International Journal of Mechanical and Production Engineering, 5(7), 91-94.

[14] Ikpe, A. E. Owunna, I. B. and Satope, P. (2017). Design optimization of a B-pillar for crashworthiness of vehicle side impact, Journal of Mechanical Engineering and Sciences, 11(2), 2693-2710.

[15] Ikpe, A. E., Efe-Ononeme, O. E. and Ariavie, G. O. (2018). Thermo-structural analysis of first stage gas turbine rotor blade materials for optimum service performance, International Journal of Engineering and Applied Sciences, 10(2), 118-130.

[16] Ikpe A. E. and Owunna, I. (2017). Design of vehicle compression springs for optimum performance in their service condition, International Journal of Engineering Research in Africa, 33, 22-34.

[17] Owunna, I., Ikpe, A. E and Achebo, J. I. (2018). 3D finite element modelling of weld bead penetration in tungsten inert gas (TIG) welding of AISI 1020 low carbon steel plate, $E u$ ropean Mechanical Science, 2(3), 96-105.

[18] Owunna, I.B. and Ikpe, A.E. (2018). Effects of parametric variations on bead width of gas tungsten arc welding of AISI 1020 low carbon steel plate, International Journal of Engineering Technology and Sciences, 5(3), 1-13.

[19] Kamanna, B., Jose, B., Shedage, A. S., Ambekar, S. G., Shinde, R. S. and Landge, S. (2017). Thermal barrier coating on IC engine piston to improve engine efficiency, International Journal of Scientific and Engineering Research, 8(3), 250-253.

[20] Owunna I., Ikpe, A., Ebunilo, P. O. and Ikpe, E. (2016). Investigation of a vehicle tie rod failure in relation to the forces acting on the suspension system, American Journal of Engineering Research, 5(6), 208-217. 